\title{
ERRATUM
}

\section{Market Efficiency in the Second-hand Market for Bulk Ships}

\author{
AROR OS ADLAND \& STEEN KOEKEBAKAR
}

Maritime Economics \& Logistics (2004) 6, 197.

doi:10.1057/palgrave.mel.9100106

Correction to: Maritime Economics and Logistics (2004) 6, 1-15.

doi:10.1057/palgrave.mel.9100093

In the above paper, an error has been identified in the spelling of the author's name. The correct spelling appears below:

ROAR O ÅDLAND 